\title{
Network Plasticity and Intraoperative Mapping for Personalized Multimodal Management of Diffuse Low-Grade Gliomas
}

\author{
Cristina Diana Ghinda ${ }^{1,2 *}$ and Hugues Duffau ${ }^{3,4}$ \\ 'Department of Neurosurgery, The Ottawa Hospital, Ottawa Hospital Research Institute, Ottawa, ON, Canada, \\ ${ }^{2}$ Neuroscience Division, University of Ottawa, Ottawa, ON, Canada, ${ }^{3}$ Department of Neurosurgery, Hôpital Gui de Chauliac, \\ Montpellier University Medical Center, Montpellier, France, ${ }^{4}$ Brain Plasticity, Stem Cells and Glial Tumors Team, National \\ Institute for Health and Medical Research (INSERM), Montpellier, France
}

Gliomas are the most frequent primary brain tumors and include a variety of different histological tumor types and malignancy grades. Recent achievements in terms of molecular and imaging fields have created an unprecedented opportunity to perform a comprehensive interdisciplinary assessment of the glioma pathophysiology, with direct implications in terms of the medical and surgical treatment strategies available for patients. The current paradigm shift considers glioma management in a comprehensive

OPEN ACCESS

Edited by:

Ziya Levent Gokaslan,

Brown University, USA

Reviewed by:

Hiroki Toda,

Kitano Hospital, Japan

Kareem Zaghloul,

National Institute of Neurological

Disorders and Stroke, USA

*Correspondence:

Cristina Diana Ghinda dghinda@toh.on.ca

Specialty section: This article was submitted to Neurosurgery,

a section of the journal

Frontiers in Surgery

Received: 09 September 2016 Accepted: 16 January 2017

Published: 31 January 2017

Citation:

Ghinda CD and Duffau H (2017) Network Plasticity and Intraoperative Mapping for Personalized Multimodal Management of Diffuse Low-Grade

Gliomas.

Front. Surg. 4:3

doi: 10.3389/fsurg.2017.00003 perspective that takes into account the intricate connectivity of the cerebral networks. This allowed significant improvement in the outcome of patients with lesions previously considered inoperable. The current review summarizes the current theoretical framework integrating the adult human brain plasticity and functional reorganization within a dynamic individualized treatment strategy for patients affected by diffuse low-grade gliomas. The concept of neuro-oncology as a brain network surgery has major implications in terms of the clinical management and ensuing outcomes, as indexed by the increased survival and quality of life of patients managed using such an approach.

Keywords: awake surgery, functional brain mapping, intraoperative mapping, anatomofunctional connectivity, low-grade gliomas, neuroplasticity, direct electrical stimulation

\section{INTRODUCTION}

Neurosurgical resection remains the standard of care for gliomas, and the extent of resection (EOR) is one of the most important factors affecting the patients' survival and quality of life for both highand low-grade gliomas (1-9). The diffuse low-grade gliomas (DLGGs) portray a distinct clinical and radiological behavior and display particular gene expression signatures. DLGG is thought to represent a chronic invasive lesion that migrates along the white matter pathways, and eventually undergoes malignant transformation leading ultimately to death (10).

The concept of individualized surgery in neuro-oncological treatment of glial tumors is based on the goal of achieving a maximal tumor resection without inducing new neurological deficits. Analogously, for tumors located in proximity to critical functional areas, the use of intraoperative cortical and subcortical electro stimulation mapping (IEM) during awake craniotomy evolved over time and allows a substantial increase in the survival and quality of life of patients $(1,6,9,11-14)$.

The joint efforts of neuroscientists, researchers, and clinicians have provided an unprecedented ability to localize lesions and to assess the human brain function at the microscopic, mesoscopic, 
and macroscopic scales (15). The resultant array of invasive and non-invasive measures allowed surgeons to push the boundaries of safe surgical resection with subsequently improved clinical outcomes. As depicted by the extensive work performed by several research groups, the concepts of brain connectome and brain plasticity represent promising notions that advanced the neurosurgical treatments available for neurosurgical patients affected by DLGG.

\section{A Dynamic Concept: Tumor Growth and Functional Neuroplasticity}

The survival benefit associated with an increased EOR has been demonstrated for both high- and low-grade gliomas; however, such oncological benefits need to take into account the risks of inducing neurological deficits. Although it is acknowledged that in DLGG, tumor infiltration follows the white matter tracts beyond the boundaries visualized on standard neuroimaging techniques, current treatment thresholds are still based on static radiological perceived boundaries. For instance, conventional radiotherapy protocols target a $2 \mathrm{~cm}$ conventional Euclidean distance around the macroscopically visible tumor, without taking into account the infiltrative and dynamic growth patterns of the lesion, thus equally radiating "non-cancerous brain tissue that could not only cause neurological deficits but also restrict the residual plasticity potential while leaving alive cancerous cells in other areas" (15).

One of glioma's hallmark properties is the ability of cancer cells to invade healthy tissue, extensive attempts having been made both on the microscopic and macroscopic scales in order to determine the underlying pathophysiology. The different mechanisms involved in the plasticity of tumor cell motility have already been summarized by Taddei et al. and Cuddapah et al. $(16,17)$. Among the different structural and cellular adaptive strategies displayed by cancer cells, enhanced cell motility as well as resistance to hypoxia and acidity represent some of the key factors allowing tumors to elude antineoplastic drugs and radiotherapy treatments. From a biological perspective, the migration and invasion of tumor cells requires an increase in cellular motility, which involves formation of actin-based dynamic protrusions of the plasma membrane (18-20). Actin represents one of the key cytoskeletal filaments and its instability caused by hypoxia or tissue injury can facilitate entry of the cell into mitosis, thereby acting as an epigenetic determinant of the cell fate (21). Also, tumor cell motility can be modulated by acidity as the assembly of actin filaments in migrating cells increases with an intracellular $\mathrm{pH}$ higher than 7.2 (16). Moreover, in vivo imaging of membrane tube development over time revealed that the microtube-connected astrocytoma cells create a multicellular anatomical network that serve as routes for brain invasion, proliferation, and communication over long distances $(18,19)$. Disconnection of astrocytoma cells by targeting their tumor microtubes was already proposed as a possible new therapeutic strategy against cancer (22). Ion channels and transporters also appear to play a major role in the invasion strategies by mediating the hydrodynamic shape and volume changes displayed by tumor cells $(17,23-26)$. For instance, $\mathrm{K}+$ and $\mathrm{Cl}-$ ions are thought to function as osmotically active ions that facilitate the dynamic cytoplasmic volume regulation occurring in tumor cells as they migrate and invade the surrounding tissue $(25,26)$.

The diffuse invasion exhibited by cancer cells can follow the same "extracellular routes of migration that are traveled by immature neurons and stem cells," which similarly migrate along extracellular routes such as intracranial vasculature and white matter tracts $(17,27)$. Although the origin of gliomas is still unknown, it likely represents a complex phenomenon involving both genetic and epigenetic factors with a suspected cellular origin from a neural stem cell or an oligodendrocyte precursor cell (27-29). In addition, tumor recurrence occurs predominantly at the primary location of the tumor for both low- and high-grade gliomas. Tumor relapses might be linked to the presence of a cell subpopulation with stem cell characteristics, labeled as glioma stem cells $(29,30)$. While multiple studies assessed the presence of tumorigenic stem cells in high-grade lesions, the occurrence of those cells has equally been reported in patients harboring LGG (30). These cells are highly resistant to conventional chemotherapeutic drugs and could equally mediate tumor recurrence following radiation therapy (31-33). Tumor cell dissemination and heterogeneity represent important aspects that should be taken into account in order to improve the medical and surgical therapeutic regimens (34). Computational models attempt to simulate the functional consequences associated with brain tumor growth by incorporating the tumor-induced plastic compensatory mechanism along with the structural and biological heterogeneity of gliomas (35).

Delineating the extent of tumor infiltration has been subject to intense research, as the boundaries between tumor and healthy tissue are difficult to detect macroscopically with current imaging techniques like functional MRI (fMRI), positron emission tomography, spectroscopy, and diffusion tensor imaging (36-38). In the case of tumor-related epilepsy, such techniques allowed to establish a link between the peritumoral tissue and the tumor-related epileptogenesis, which can explain both the antiepileptic effects of oncological treatments (39-41) and the increase in seizure frequency as tumors progress (42). As both infiltrated peritumoral tissue and connectivity changes have been related to the development of seizures, understanding brain reorganization mechanisms has important clinical implications for controlling refractory seizures $(43,44)$. Recent studies investigated the role of functional network synchronizability to predict spread of seizures before they begin and also described control regions that strongly synchronize or desynchronize network dynamics (45). By investigating time-varying functional networks, the dynamic changes in the topographical organization of different functional networks could have wide applicability in mapping the plastic reorganization occurring in other diseases such as stroke and trauma (46-51). Similarly, brain tumors may also induce changes in large-scale functional connectivity (FC) that should be taken into account by the surgical approach (52). For instance, the complex language network reorganization occurring in the setting of a dominant left hemisphere DLGG infiltrating classical "Broca" and "Wernicke" areas (53-55) allow tumor resection with no functional consequences as depicted in the case illustrated in Figure 1. Thus, understanding the underlying neuromodulation principles governing the 


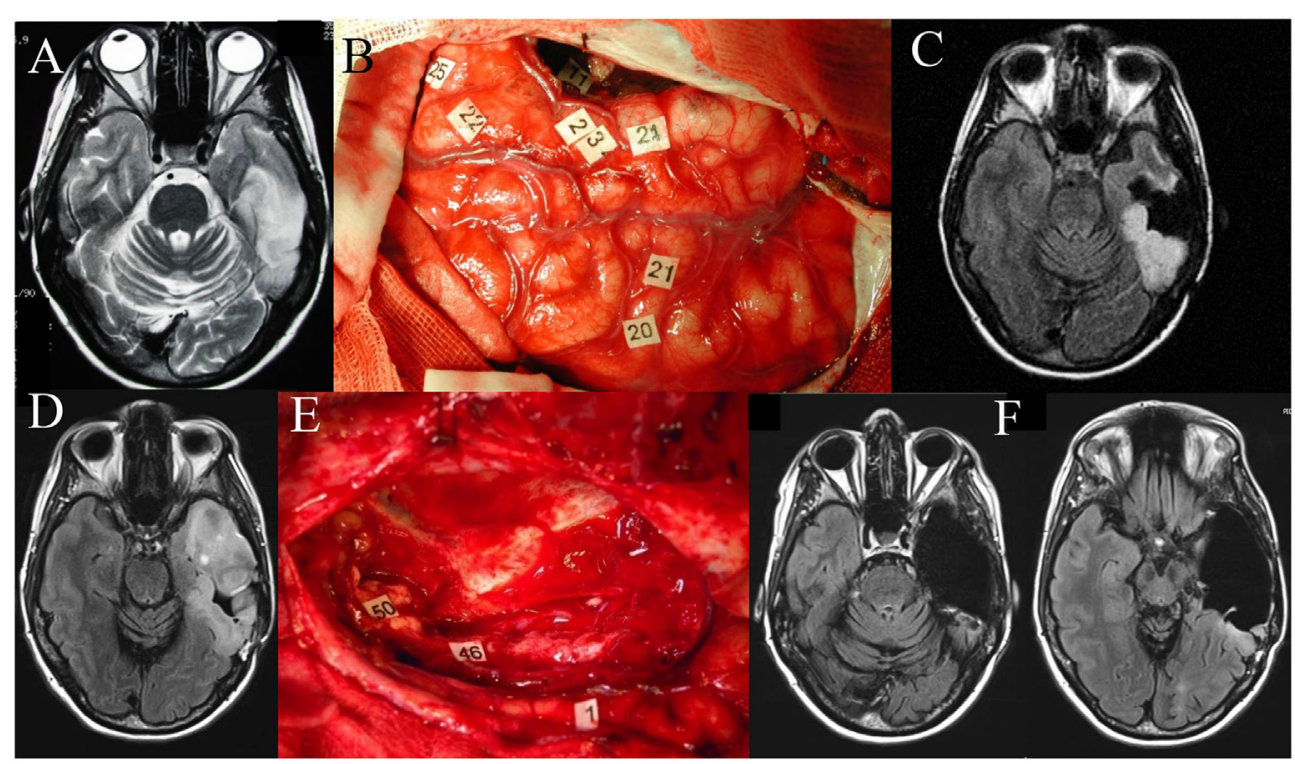

FIGURE 1 | Left temporal diffuse low-grade glioma (DLGG). Axial FLAIR-weighted MRI (A) showing a left temporal DLGG in a 36-year-old patient who presented with isolated seizures and no neurological deficits. Intraoperative photograph during the first awake surgery (B), after resection was performed according to individual functional boundaries. Stimulation mapping demonstrated the persistence of eloquent cortical areas in the temporal lobe (tags $22,23,24,25)$ as well as subcortical fibers (tag 11, corresponding to the inferior longitudinal fascicle) still critical for language function. Postoperative axial FLAIR-weighted MRI (C) revealing a partial resection, with a posterior residual tumor voluntarily left for functional reasons. The diagnosis of DLGG was confirmed, and the patient resumed a normal familial, social, and professional life. Ten years later, epileptic seizures recurred concomitantly with an imaging progression as demonstrated on the axial FLAIRweighted MRI (D). Reoperation was proposed to the patient. Intraoperative photograph (E) during the second awake surgery, after resection was performed according to the new individual functional boundaries. Electrocortical stimulation mapping revealed brain reorganization, allowing the achievement of a significantly wider resection compared to the first surgery. Of note, at the subcortical level, stimulation of the left inferior fronto-occipital fascicle (IFOF) (46 and 50) elicited semantic paraphasia when stimulated at the end of surgery. Thus, resection of the anterior part of the inferior longitudinal fascicle was possible given the compensation provided by the direct ventral pathway represented by the left IFOF. Postoperative axial FLAIR-weighted MRI (F) performed 3 months after the second surgery showing a complete resection, made possible due to mechanisms of neuroplasticity, in a patient who returned to a normal life with no permanent neurological deficit.

neurosynaptic networks could lead to new methods for functional restoration $(48,49,53)$.

Cerebral plasticity represents the "continuous process allowing short-term, middle-term, and long-term remodeling of neurosynaptic maps, to optimize the functioning of brain networks" (56). The concept of adult neuroplasticity exemplifies the strong interplay between the cortex and other structures provided by the myriad of cortical and subcortical connections. The underlying mechanisms for this functional reorganization and brain plasticity are not fully elucidated, and multiple theories have been proposed such as modulation of synaptic efficacy, neurogenesis, cortical hyperexcitability, redistribution, unmasking of latent networks, and establishment of new functional connections (51,57-61). Although mounting evidence depict functional reorganization in the setting of a surgical intervention, the concept of brain plasticity in the context of DLGG is still controversial (62). Nonetheless, our current understanding of the morphological, biochemical, and connectivity changes occurring in the setting of a tumor is still in its infancy and long-term large multicenter studies incorporating longitudinal multimodal investigations will likely allow us to gather more objective evidence and improve our understanding of the underlying mechanisms.
This approach facilitates the concepts of "functional neurooncology" and of "preventive glioma surgery" in order to achieve earlier and more complete resections, while giving the patients the opportunity to enjoy a normal life. Understanding the individual organization of the cortical and subcortical connectivity is essential to optimize the risk-benefit ratio of glioma surgery (63). Prominent experts in this field suggest an integration of the conceptual achievements in the neuroscience, neuroimaging, and genetic fields, in order to create a holistic personalized treatment strategy incorporating "the course of this chronic disease, reaction brain remapping, and oncofunctional modulation elicited by serial treatments" (10).

\section{Connectomics and Glioma Surgery}

Functional connectivity is a measure used to express the degree of communication between brain areas and thus to describe brain networks (64). One of the main proposed mechanisms of adult plasticity reposes on the connectome concept where the brain processing relies on "dynamic large-scale, parallel subcircuits able to interact and to compensate themselves following cerebral injury" $(65,66)$. The concept of brain connectome depicts the dynamical structural and functional neural networks that form at multiple spatial and temporal scales (67). While it is possible 
to portray structural networks delineating anatomical connectivity with deterministic tractography-derived fiber tracts (68), "functional networks" are derived from statistical estimates of time series data such as resting-state fMRI (69). For instance, using multimodal magnetic resonance images derived from the Human Connectome Project, Glasser and colleagues performed a multimodal parcelation of distinct cortical areas using an objective, semiautomated neuroanatomical approach and a robust machine-learning classifier (70). Although such non-invasive imaging studies outline a detailed non-invasive mapping of the macroscopic functional connectome, it provides just one view of the "complete" brain connectome and cannot provide the direct neuronal activity flow available through electrophysiological techniques $(67,71)$.

Brain tumors alter the normal structural and FC of the brain, consequently impacting the normal functioning of the brain. Altered FC in patients with brain tumors affects not only the tumor area but also other brain areas, as demonstrated through different imaging modalities (72-77). For instance, changes in resting-state networks in patients with tumors localized in the left hemisphere were observed in the contralateral side and correlated with alterations in some cognitive functions even before the onset of major symptoms (74). Intrinsic FC measures can also predict surgical outcome, and thereby could "provide information regarding the residual presence of function and also could define the extent of brain tumor invasion that may not be evident on structural MRI” (78).

As described by De Benedictis and Duffau, the classical "topological" representation ought to be replaced by a "hodotopical" framework, which takes into account the changes occurring in the large-scale networks of the brain (65). Only by acknowledging the complex cortico-subcortical network of the brain, the clinicians could further understand and take into account the dynamical neural processes occurring at distinct spatial and temporal scales (79). The functional connectome framework refined our understanding of functional localization as evidenced through the contemporary concepts of language organization, namely, that neuronal groups participate as components of a network allowing reorganization and recruitment of parallel circuits in the setting of injury (80-83).

Considering glioma surgery as "brain networks surgery" has led not only to a dramatic decrease of permanent neurologic impairment $(<2 \%$ in series using intraoperative corticosubcortical mapping) but also to improvement of higher order functions such as working memory, neurocognitive functions, and emotions and behavior, as evidenced by postoperative neuropsychological assessments following surgery (84). Therefore, the concept of neuro-oncology as a brain network surgery has major implications in terms of the clinical management and ensuing outcomes, as indexed by the increased survival and quality of life of patients managed using such an approach.

\section{Awake Craniotomy and Intraoperative Mapping}

Although the art and science of brain mapping was once the purview of epilepsy surgeons, the use of this technique in the neuro-oncological field had seen an exponential increase over the last decades. Proper choice and execution of brain mapping techniques has improved the precision and safety of the surgical treatment for some of the most challenging cases and can currently allow a more radical surgical resection than indicated by presumed preoperative functional localization. This entails an optimization of the intraoperative tests' selection based on the functional cortico-subcortical networks expected to be encountered as well as on the specific preoperative neurological and neuropsychological assessments of each patient (85-87).

Although many promising brain mapping techniques are currently being refined, the large interindividual differences between healthy and diseased brain preclude the ability to reliably identify standard imaging-based biomarkers for functional connectomics $(88,89)$. As such, cortical and subcortical mapping via direct electrical stimulation continues to remain the most reliable approach for accurate localization of highly functional centers specific to each patient; the usefulness of this technique being described even for children (90). Furthermore, the continuous assessment of cognitive and neurophysiological parameters provides the neurosurgeon with immediate feedback on the impact of his/her intervention.

The concept of "eloquent" cortex depends on the view that, although all cortical areas are "capable of being engaged in useful function, some brain regions are clearly more critical than others" (91), causing some degree of functional decline if resected or disconnected. This framework shift has direct implications in the clinical practice as the presumed eloquence represents a modifiable risk factor for survival $(92,93)$. Although a detailed knowledge of both cortical and subcortical anatomical structures represents the cornerstone of neurosurgery, understanding the underlying functional correlations provide the fine details of the relationship between the lesion to be managed and the healthy brain (94). Figure 1 shows an illustrative case depicting the importance of performing intraoperative mapping of cortical and subcortical fibers in a patient with a left temporal DLGG. As portrayed, the respect of functional boundaries during the first surgery allowed the patient to enjoy a normal life for 10 years, whereas the language network reorganization occurring in the setting of a slowly growing tumor allowed subsequent resection of tumoral tissue at sites where functionality prevented tumor resection initially (Figure 1).

Despite the fact that the precise influence on the electrophysiological state of brain's networks and the biophysical modeling of the electrode-tissue interface is not well elucidated (95), direct electrical stimulation represents a highly reliable and reproducible technique $(58,95-101)$. IEM has equally allowed to increase the quality of life for patients affected by a glioma in the non-dominant hemisphere by testing functions such as spatial awareness (102) or even mentalizing (103) to avoid injuring the networks involved in those functions. Furthermore, IEM during awake craniotomy allows the unique opportunity to assess and validate the anatomo-functional connectivity for multimodal systems such as sensorimotor, language, visuospatial, and sociocognitive systems (82) providing a real-time understanding of the individual organization of both cortical epicenters and subcortical connectivity (104). We can envisage the future development of platforms allowing neurosurgeons to link the intraoperative 
cortical stimulation results with macroscopic neuronal network models and use connectivity-based modeling to predict functional changes.

Several manuscripts provide a comprehensive overview of the methods and technical nuances proposed for a maximal safe resection during awake brain tumor surgery (105-107). There is increasing evidence that this technique allows to improve the outcomes by maximizing the EOR while preserving functional cortex in both low- and high-grade gliomas (1, 6, 9, 108, 109). Other benefits associated with this technique are shorter hospital stay, less blood loss, shorter operative time, reduced pain and anxiety, cost effectiveness, as well as lower complications and morbidity $(110,111)$. Nonetheless, careful preoperative planning by a dedicated multidisciplinary team with an informed patient remains an important prerequisite for a successful awake craniotomy (90).

\section{CONCLUSION}

The paradigm shift encouraging the translation of the most recent findings in the field of neurological science to the clinical setting allowed a better understanding of the interactions between the infiltrative and dynamic growth patterns of

\section{REFERENCES}

1. Sanai N, Berger MS. Extent of resection influences outcomes for patients with gliomas. Rev Neurol (2011) 167(10):648-54. doi:10.1016/j.neurol. 2011.07.004

2. Almeida JP, Chaichana KL, Rincon-Torroella J, Quinones-Hinojosa A. The value of extent of resection of glioblastomas: clinical evidence and current approach. Curr Neurol Neurosci Rep (2015) 15(2):517. doi:10.1007/ s11910-014-0517-x

3. Chaichana KL, Jusue-Torres I, Navarro-Ramirez R, Raza SM, PascualGallego M, Ibrahim A, et al. Establishing percent resection and residual volume thresholds affecting survival and recurrence for patients with newly diagnosed intracranial glioblastoma. Neuro Oncol (2014) 16(1):113-22. doi:10.1016/j.wneu.2014.01.019

4. Ius T, Isola M, Budai R, Pauletto G, Tomasino B, Fadiga L, et al. Lowgrade glioma surgery in eloquent areas: volumetric analysis of extent of resection and its impact on overall survival. A single-institution experience in 190 patients: clinical article. J Neurosurg (2012) 117(6):1039-52. doi:10.3171/2012.8.JNS12393

5. Capelle L, Fontaine D, Mandonnet E, Taillandier L, Golmard JL, Bauchet L, et al. Spontaneous and therapeutic prognostic factors in adult hemispheric World Health Organization Grade II gliomas: a series of 1097 cases: clinical article. J Neurosurg (2013) 118(6):1157-68. doi:10.3171/2013. 1.JNS121

6. Yordanova Y, Moritz-Gasser S, Duffau H. Awake surgery for WHO grade II gliomas within "noneloquent" areas in the left dominant hemisphere: toward a "supratotal" resection. J Neurosurg (2011) 115(2):232-9. doi:10.3171/2011.3.JNS101333

7. Ahmadi R, Dictus C, Hartmann C, Zürn O, Edler L, Hartmann M, et al. Long-term outcome and survival of surgically treated supratentorial low-grade glioma in adult patients. Acta Neurochir (2009) 151:1359-65. doi:10.1007/s00701-009-0435-x

8. McGirt MJ, Chaichana KL, Attenello FJ, Weingart JD, Than K, Burger PC, et al. Extent of surgical resection is independently associated with survival in patients with hemispheric infiltrating low-grade gliomas. Neurosurgery (2008) 63:700-8. doi:10.1227/01.NEU.0000325729.41085.73

9. Sanai N, Berger MS. Glioma extent of resection and its impact on patient outcome. Neurosurgery (2008) 62:753-64. doi:10.1227/ 01.neu.0000318159.21731.cf
DLGG and brain adaptation mechanisms (such as neuroplasticity and network reorganization). Using multimodal imaging studies and different neurophysiological tools does not take the place of a meticulous surgical technique and an extensive knowledge of the functional-structural anatomy in order to protect the cortical and subcortical FC. The concept of awake craniotomy as a brain network surgery allows neurosurgeons to adequately assess the dichotomy between the neurological and oncological risk management. It also highlights the delicate function-oncological balance that needs to be maintained, as it will ultimately reflect on the quality of life and overall survival rate of the patients. A joint multidisciplinary approach where the emerging advancements from different fields are integrated in clinical practice in a personalized dynamic approach using ongoing feedback from clinical-radiological monitoring could provide more effective treatment options for patients affected by DLGG as already demonstrated by the increased survival and quality of life of patients treated using such a treatment strategy.

\section{AUTHOR CONTRIBUTIONS}

All authors have made substantial, direct, and intellectual contribution to the work and approved it for publication.

10. Duffau H, Taillandier L. New concepts in the management of diffuse low-grade glioma: proposal of a multistage and individualized therapeutic approach. Neuro Oncol (2015) 17(3):332-42. doi:10.1093/neuonc/nou153

11. Duffau H, Lopez M, Arthuis F, Bitar A, Sichez J, Effenterre R, et al. Contribution of intraoperative electrical stimulations in surgery of low grade gliomas: a comparative study between two series without (1985-96) and with (1996-2003) functional mapping in the same institution. J Neurol Neurosurg Psychiatry (2005) 76:845-51. doi:10.1136/jnnp.2004.048520

12. Smith JS, Chang EF, Lamborn KR, Chang SM, Prados MD, Cha S, et al. Role of extent of resection in the long-term outcome of low-grade hemispheric gliomas. J Clin Oncol (2008) 26(8):1338-45. doi:10.1200/JCO. 2007.13.9337

13. Duffau H, Gatigno P, Manddonet E, Capelle L, Taillander L. Intra-operative subcortical stimulation mapping of language pathways in a consecutive series of 115 patients with Grade II glioma in the left dominant hemisphere. J Neurosurg (2008) 109:610-701. doi:10.3171/JNS/2008/109/9/0461

14. De Witt Hamer PC, Robles SG, Zwinderman AH, Duffau H, Berger MS. Impact of intraoperative stimulation brain mapping on glioma surgery outcome: a meta-analysis. J Clin Oncol (2012) 30(20):2559-65. doi:10.1200/ JCO.2011.38.4818

15. Mosayebi P, Cobzas D, Murtha A, Jagersand M. Tumor invasion margin on the Riemannian space of brain fibers. Med Image Anal (2012) 16(2):361-73. doi:10.1016/j.media.2011.10.001

16. Taddei ML, Giannoni E, Comito G, Chiarugi P. Microenvironment and tumor cell plasticity: an easy way out. Cancer Lett (2013) 341:80-96. doi:10.1016/j.canlet.2013.01.042

17. Cuddapah VA, Robel S, Watkins S, Sontheimer H. A neurocentric perspective on glioma invasion. Nat Rev Neurosci (2014) 15:455-65. doi:10.1038/ nrn3765

18. Osswald M, Solecki G, Wick W, Winkler F. A malignant cellular network in gliomas: potential clinical implications. Neuro Oncol (2016) 18(4):479-85. doi:10.1093/neuonc/now014

19. Osswald M, Jung E, Sahm F, Solecki G, Venkataramani V, Blaes J, et al. Brain tumour cells interconnect to a functional and resistant network. Nature (2015) 528(7580):93-8. doi:10.1038/nature16071

20. Stylli SS, Kaye AH, Lock P. Invadopodia: at the cutting edge of tumour invasion. J Clin Neurosci (2008) 15:725-37. doi:10.1016/j.jocn.2008.03.003

21. Diaz JA, Murillo MF, Mendoza JA, Barreto AM, Poveda LS, Sanchez LK, et al. Human somatic cells acquire the plasticity to generate embryoid-like 
metamorphosis via the actin cytoskeleton in injured tissues. Am J Stem Cells (2016) 5(2):53-73.

22. Jordan MA, Wilson L. Microtubules as a target for anticancer drugs. Nat Rev Cancer (2014) 4:253-65. doi:10.1038/nrc1317

23. Cuddapah VA, Sontheimer H. Ion channels and transporters in cancer. 2. Ion channels and the control of cancer cell migration. Am J Physiol Cell Physiol (2011) 301(3):C541-9. doi:10.1152/ajpcell.00102.2011

24. Thompson EG, Sontheimer H. A role for ion channels in perivascular glioma invasion. Eur Biophys J (2016) 45(7):635-48. doi:10.1007/s00249016-1154-x

25. Turner KL, Sontheimer $\mathrm{H}$. Cl- and $\mathrm{K}+$ channels and their role in primary brain tumour biology. Philos Trans $R$ Soc Lond B Biol Sci (2014) 369(1638):20130095. doi:10.1098/rstb.2013.0095

26. Sontheimer H. An unexpected role for ion channels in brain tumour metastasis. Exp Biol Med (2009) 233(7):779-91. doi:10.3181/0711-MR-308

27. Lei L, Sonabend AM, Guarnieri P, Soderquist C, Ludwig T, Rosenfeld S, et al. Glioblastoma models reveal the connection between adult glial progenitors and the proneural phenotype. PLoS One (2011) 6(5):e20041. doi:10.1371/ journal.pone. 0020041

28. Darlix A, Gozé C, Rigau V, Bauchet L, Taillandier L, Duffau H. The etiopathogenesis of diffuse low-grade gliomas. Crit Rev Oncol Hematol (2017) 109:51-62. doi:10.1016/j.critrevonc.2016

29. Riemenschneider MJ, Jeuken JW, Wesseling P, Reifenberger G. Molecular diagnostics of gliomas: state of the art. Acta Neuropathol (2010) 120(5):56784. doi:10.1007/s00401-010-0736-4

30. Bourkoula E, Mangoni D, Ius T, Pucer A, Isola M, Musiello D, et al. Gliomaassociated stem cells: a novel class of tumor-supporting cells able to predict prognosis of human low-grade gliomas. Stem Cells (2014) 32:1239-53. doi:10.1002/stem.1605

31. Murat A, Migliavacca E, Gorlia T, Lambiv WL, Shay T, Hamou MF, et al. Stem cell-related "self-renewal" signature and high epidermal growth factor receptor expression associated with resistance to concomitant chemoradiotherapy in glioblastoma. J Clin Oncol (2008) 26:3015-24. doi:10.1200/ JCO.2007.15.7164

32. Tamura K, Aoyagi M, Ando N, Ogishima T, Wakimoto H, Yamamoto M, et al. Expansion of CD133-positive glioma cells in recurrent de novo glioblastomas after radiotherapy and chemotherapy. Laboratory investigation. J Neurosurg (2013) 119:1145-55. doi:10.3171/2013.7.JNS122417

33. Bao S, Wu Q, McLendon RE, Hao Y, Shi Q, Hjelmeland AB, et al. Glioma stem cells promote radioresistance by preferential activation of the DNA damage response. Nature (2006) 444:756-60. doi:10.1038/nature05236

34. Antonopoulos M, Stamatakos G. In silico neuro-oncology: Brownian motion-based mathematical treatment as a potential platform for modeling the infiltration of glioma cells into normal brain tissue. Cancer Inform (2015) 14(S4):33-40. doi:10.4137/CIN.S19341

35. Szalisznyo K, Silverstein DN, Duffau H, Smits A. Pathological neural attractor dynamics in slowly growing gliomas supports an optimal time frame for white matter plasticity. PLoS One (2013) 8(7):e69798. doi:10.1371/ journal.pone. 0069798

36. Zehri AH, Ramey W, Georges JF, Mooney MA, Martirosyan NL, Preul MC, et al. Neurosurgical confocal endomicroscopy: a review of contrast agents, confocal systems, and future imaging modalities. Surg Neurol Int (2014) 5:60. doi:10.4103/2152-7806.131638

37. Verburg N, Pouwels PJ, Boellaard R, Barkhof F, Hoekstra OS, Reijneveld JC, et al. Accurate delineation of glioma infiltration by advanced PET/ MR neuro-imaging (FRONTIER study): a diagnostic study protocol. Neurosurgery (2016) 79(4):535-40. doi:10.1227/NEU.0000000000001355

38. Barone DG, Lawrie TA, Hart MG. Image guided surgery for the resection of brain tumours. Cochrane Database Syst Rev (2014) 1:CD009685. doi:10.1002/14651858.CD009685.pub2

39. Englot DJ, Berger MS, Barbaro NM, Chang EF. Factors associated with seizure freedom in the surgical resection of glioneuronal tumors. Epilepsia (2012) 53(1):51-7. doi:10.1111/j.1528-1167.2011.03269.x

40. Englot DJ, Han SJ, Berger MS, Barbaro NM, Chang EF. Extent of surgical resection predicts seizure freedom in low-grade temporal lobe brain tumors. Neurosurgery (2012) 70(4):921-8. doi:10.1227/NEU.0b013e31823c3a30

41. Sherman JH, Moldovan K, Yeoh HK, Starke RM, Pouratian N, Shaffrey M, et al. Impact of temozolomide chemotherapy on seizure frequency in patients with low-grade gliomas. J Neurosurg (2011) 114(6):1617-21. doi:10.3171/2010.12.JNS101602

42. Rosati A, Tomassini A, Pollo B, Ambrosi C, Schwarz A, Padovani A, et al. Epilepsy in cerebral glioma: timing of appearance and histological correlations. J Neurooncol (2009) 93(3):395-400. doi:10.1007/s11060009-9796-5

43. De Grott M, Reijneveld J, Aronica E, Heimans J. Epilepsy in patients with a brain tumour: focal epilepsy requires focused treatment. Brain (2012) 135(4):1002-16. doi:10.1093/brain/awr310

44. Pallud J, Capelle L, Huberfeld G. Tumoral epileptogenicity: how does it happen? Epilepsia (2013) 54(S9):30-4. doi:10.1111/epi.12440

45. Khambhati AN, Davis KA, Lucas TH, Litt B, Bassett DS. Virtual cortical resection reveals push-pull network control preceding seizure evolution. Neuron (2016) 91(5):1170-82. doi:10.1016/j.neuron.2016.07.039

46. Chang EH, Adorjan I, Mundim MV, Sun B, Dizon ML, Szele FG. Traumatic brain injury activation of the adult subventricular zone neurogenic niche. Front Neurosci (2016) 10:332. doi:10.3389/fnins.2016.00332

47. Nudo RJ. Recovery after brain injury: mechanisms and principles. Front Hum Neurosci (2013) 7:887. doi:10.3389/fnhum.2013.00887

48. Wang L, Yu C, Chen H, Qin W, He Y, Fan F, et al. Dynamic functional reorganization of the motor execution network after stroke. Brain (2010) 133(4):1224-38. doi:10.1093/brain/awq043

49. Mandonnet E, Duffau H. Understanding entangled cerebral networks: a prerequisite for restoring brain function with brain-computer interfaces. Front Syst Neurosci (2014) 8:82. doi:10.3389/fnsys.2014.00082

50. Herbet G, Maheu M, Costi E, Lafargue G, Duffau H. Mapping neuroplastic potential in brain-damaged patients. Brain (2016) 139(3):829-44. doi:10.1093/brain/awv394

51. Castellanos NP, Leyva I, Buldú JM, Bajo R, Paúl N, Cuesta P. Principles of recovery from traumatic brain injury: reorganization of functional networks. Neuroimage (2011) 55(3):1189-99. doi:10.1016/j.neuroimage.2010. 12.046

52. Douw L, Baayen H, Bosma I, Klein M, Vandertop P, Heimans J, et al. Treatment-related changes in functional connectivity in brain tumor patients: a magnetoencephalography study. Exp Neurol (2008) 212(2):285-90. doi:10.1016/j.expneurol.2008.03.013

53. Duffau H. Diffuse low-grade gliomas and neuroplasticity. Diagn Interv Imaging (2014) 95(10):945-55. doi:10.1016/j.diii.2014.08.001

54. Duffau H, Moritz-Gasser S, Mandonnet E. A re-examination of neural basis of language processing: proposal of a dynamic hodotopical model from data provided by brain stimulation mapping during picture naming. Brain Lang (2014) 131:1-10. doi:10.1016/j.bandl.2013.05.011

55. Herbet G, Lafargue G, Bonnetblanc F, Moritz-Gasser S, Menjot de Champfleur N, Duffau H. Interfering a dual-stream model of mentalizing from associative white matter fibres disconnection. Brain (2014) 137(P3):944-59. doi:10.1093/brain/awt370

56. Duffau H. Lessons from brain mapping in surgery for low-grade glioma: insights into associations between tumour and brain plasticity. Lancet Neurol (2005) 4:476-86. doi:10.1016/S1474-4422(05)70140-X

57. Duffau $\mathrm{H}$. Acute functional reorganisation of the human motor cortex during resection of central lesions: a study using intraoperative brain mapping. J Neurol Neurosurg Psychiatry (2001) 70(4):506-13. doi:10.1136/ jnnp.70.4.506

58. Desmurget M, Bonnetblanc F, Duffau H. Contrasting acute and slow-growing lesions: a new door to brain plasticity. Brain (2007) 130:898-914. doi:10.1093/brain/awl300

59. Reinges MHT, Krings T, Rohde V, Hans F-J, Willmes K, Thron A, et al. Prospective demonstration of short-term motor plasticity following acquired central pareses. Neuroimage (2005) 24:1248-55. doi:10.1016/ j.neuroimage.2004.11.002

60. Martino J, Taillandier L, Moritz-Gasser S, Gatignol P, Duffau H. Re-operation is a safe and effective therapeutic strategy in recurrent WHO grade II gliomas within eloquent areas. Acta Neurochir (2009) 151:427-36. doi:10.1007/ s00701-009-0232-6

61. Robles SG, Gatignol P, Lehéricy S, Duffau H. Long-term brain plasticity allowing a multistage surgical approach to World Health Organization Grade II gliomas in eloquent areas. J Neurosurg (2008) 109:615-24. doi:10.3171/ JNS/2008/109/10/0615 
62. Zadeh G, Khan OH, Vogelbaum M, Schiff D. Much debated controversies of diffuse low-grade gliomas. Neuro Oncol (2015) 17(3):323-6. doi:10.1093/ neuonc/nou368

63. Duffau H. A new philosophy in surgery for diffuse low-grade glioma (DLGG): oncological and functional outcomes. Neurochirurgie (2013) 59(1):2-8. doi:10.1016/j.neuchi.2012.11.001

64. Reijneveld JC, Ponten SC, Berendse HW, Stam CJ. The application of graph theoretical analysis to complex networks in the brain. Clin Neurophysiol (2007) 118(11):2317-31. doi:10.1016/j.clinph.2007.08.010

65. De Benedictis A, Duffau H. Brain hodotopy: from esoteric concept to practical surgical applications. Neurosurgery (2011) 68:1709-23. doi:10.1227/ NEU.0b013e3182124690

66. Duffau H. The huge plastic potential of adult brain and the role of connectomics: new insights provided by serial mappings in glioma surgery. Cortex (2014) 58:325-37. doi:10.1016/j.cortex.2013.08.005

67. Smith SM, Vidaurre D, Beckmann CF, Glasser MF, Jenkinson M, Miller $\mathrm{KL}$, et al. Functional connectomics from resting-state fMRI. Trends Cogn Sci (2013) 17(12):666-82. doi:10.1016/j.tics.2013.09.016

68. Gong G, He Y, Concha L, Lebel C, Gross DW, Evans AC, et al. Mapping anatomical connectivity patterns of human cerebral cortex using in vivo diffusion tensor imaging tractography. Cereb Cortex (2009) 19(3):536-43. doi:10.1093/cercor/bhn102

69. van den Heuvel MP, Sporns O. Network hubs in the human brain. Trends Cogn Sci (2013) 17(12):683-96. doi:10.1016/j.tics.2013.09.012

70. Glasser MF, Coalson TS, Robinson EC, Hacker CD, Harwell J, Yacoub E, et al. A multi-modal parcellation of human cerebral cortex. Nature (2016) 536(7615):171-8. doi:10.1038/nature18933

71. Kennedy H, Knoblauch K, Toroczkai Z. Why data coherence and quality is critical for understanding interareal cortical networks. Neuroimage (2013) 80:37-45. doi:10.1016/j.neuroimage.2013.04.031

72. Bartolomei F, Bosma I, Klein M, Baayen JC, Reijneveld JC, Postma TJ, et al. Disturbed functional connectivity in brain tumour patients: evaluation by graph analysis of synchronization matrices. Clin Neurophysiol (2006) 117(9):2039-49. doi:10.1016/j.clinph.2006.05.018

73. Esposito R, Mattei PA, Briganti C, Romani GL, Tartaro A, Caulo M. Modifications of default-mode network connectivity in patients with cerebral glioma. PLoS One (2012) 7(7):e40231. doi:10.1371/journal.pone.0040231

74. Maesawa S, Bagarinao E, Fujii M, Futamura M, Motomura K, Watanabe H, et al. Evaluation of resting state networks in patients with gliomas: connectivity changes in the unaffected side and its relation to cognitive function. PLoS One (2015) 10(2):e0118072. doi:10.1371/journal.pone.0118072

75. Maesawa S, Bagarinao E, Fujii M, Futamura M, Wakabayashi T. Use of network analysis to establish neurosurgical parameters in gliomas and epilepsy. Neurol Med Chir (2016) 56(4):158-69. doi:10.2176/nmc.ra. 2015-0302

76. Harris RJ, Bookheimer SY, Cloughesy TF, Kim HJ, Pope WB, Lai A, et al. Altered functional connectivity of the default mode network in diffuse gliomas measured with pseudo-resting state fMRI. J Neurooncol (2014) 116(2):373-9. doi:10.1007/s11060-013-1304-2

77. Zhang H, Shi Y, Yao C, Tang W, Yao D, Zhang C, et al. Alteration of the intra- and cross-hemisphere posterior default mode network in frontal lobe glioma patients. Sci Rep (2016) 6:26972. doi:10.1038/srep26972

78. Martino J, Honma SM, Findlay AM, Guggisberg AG, Owen JP, Kirsch $\mathrm{HE}$, et al. Resting functional connectivity in patients with brain tumors in eloquent areas. Ann Neurol (2011) 69:521-32. doi:10.1002/ana.22167

79. Sporns O. The human connectome: a complex network. Ann N Y Acad Sci (2011) 1224:109-25. doi:10.1111/j.1749-6632.2010.05888.x

80. Matsumoto R, Nair DR, LaPresto E, Najm I, Bingaman W, Shibasaki H, et al. Functional connectivity in the human language system: a cortico-cortical evoked potential study. Brain (2004) 127(10):2316-30. doi:10.1093/brain/ awh246

81. Ding N, Melloni L, Zhang H, Tian X, Poeppel D. Cortical tracking of hierarchical linguistic structures in connected speech. Nat Neurosci (2016) 19(1):158-64. doi:10.1038/nn.4186

82. Duffau H. Stimulation mapping of white matter tracts to study brain functional connectivity. Nat Rev Neurol (2015) 11(5):255-65. doi:10.1038/ nrneurol.2015.51

83. Babajani-Feremi A, Narayana S, Rezaie R, Choudhri AF, Fulton SP, Boop FA, et al. Language mapping using high gamma electrocorticography,
fMRI, and TMS versus electrocortical stimulation. Clin Neurophysiol (2016) 127(3):1822-36. doi:10.1016/j.clinph.2015.11.017

84. Duffau $H$. The challenge to remove diffuse low-grade gliomas while preserving brain functions. Acta Neurochir (Wien) (2012) 154(4):569-74. doi:10.1007/s00701-012-1275-7

85. De Witte E, Satoer D, Colle H, Robert E, Visch-Brink E, Mariën P. Subcortical language and non-language mapping in awake brain surgery: the use of multimodal tests. Acta Neurochir (Wien) (2015) 157(4):577-88. doi:10.1007/ s00701-014-2317-0

86. Fernández Coello A, Moritz-Gasser S, Martino J, Martinoni M, Matsuda R, Duffau $H$. Selection of intraoperative tasks for awake mapping based on relationships between tumor location and functional networks. J Neurosurg (2013) 119(6):1380-94. doi:10.3171/2013.6.JNS122470

87. Teixidor P, Gatignol P, Leroy M, Masuet-Aumatell C, Capelle L, Duffau H. Assessment of verbal working memory before and after surgery for lowgrade glioma. J Neurooncol (2007) 81(3):305-13. doi:10.1007/s11060-0069233-y

88. Zuo XN, Anderson JS, Bellec P, Birn RM, Biswal BB, Blautzik J, et al. An open science resource for establishing reliability and reproducibility in functional connectomics. Sci Data (2014) 1:140049. doi:10.1038/sdata. 2014.49

89. Duffau H. A two-level model of interindividual anatomo-functional variability of the brain and its implications for neurosurgery. Cortex (2017) 86:303-13. doi:10.1016/j.cortex.2015.12.009

90. Balogun JA, Khan OH, Taylor M, Dirks P, Der T, Carter Snead III $\mathrm{O}$, et al. Pediatric awake craniotomy and intra-operative stimulation mapping. J Clin Neurosci (2014) 21(11):1891-4. doi:10.1016/j.jocn.2014. 07.013

91. Boling W, Olivier A. Anatomy of important functioning cortex. In: Byrne RW, editor. Functional Mapping of the Cerebral Cortex: Safe Surgery in Eloquent Brain. Switzerland: Springer International Publishing (2016). 23 p.

92. Jakola AS, Unsgård G, Myrmel KS, Kloster R, Torp SH, Lindal S, et al. Low grade gliomas in eloquent locations - implications for surgical strategy, survival and long term quality of life. PLoS One (2012) 7(12):e51450. doi:10.1371/journal.pone.0051450

93. Duffau $H$. The rationale to perform early resection in incidental diffuse low-grade glioma: toward a "preventive surgical neurooncology". World Neurosurg (2013) 80(5):e115-7. doi:10.1016/j.wneu.2012.06.036

94. Campero A, Ajler P, Emmerich J, Goldschmidt E, Martins C, Rhoton A. Brain sulci and gyri: a practical anatomical review. J Clin Neurosci (2014) 21(12):2219-25. doi:10.1016/j.jocn.2014.02.024

95. Vincent M, Rossel O, Hayashibe M, Herbet G, Duffau H, Guiraud D, et al. The difference between electrical microstimulation and direct electrical stimulation - towards new opportunities for innovative functional brain mapping? Rev Neurosci (2016) 27(3):231-58. doi:10.1515/revneuro-2015-0029

96. Berger MS, Rostomily RC. Low grade gliomas: functional mapping resection strategies, extent of resection, and outcome. J Neurooncol (1997) 34:85-101. doi:10.1023/A:1005715405413

97. Duffau H, Gatignol P, Mandonnet E, Peruzzi P, Tzourio-Mazoyer N, Capelle L. New insights into the anatomo-functional connectivity of the semantic system: a study using cortico-subcortical electrostimulations. Brain (2005) 128:797-810. doi:10.1093/brain/awh423

98. Borchers S, Himmelbach M, Logothetis N, Karnath HO. Direct electrical stimulation of human cortex - the gold standard for mapping brain functions? Nat Rev Neurosci (2012) 13:63-70. doi:10.1038/nrn3140

99. Desmurget M, Song Z, Mottolese C, Sirigu A. Re-establishing the merits of electrical brain stimulation. Trends Cogn Sci (2013) 17:442-9. doi:10.1016/ j.tics.2013.07.002

100. Keller CJ, Honey CJ, Mégevand P, Entz L, Ulbert I, Mehta AD. Mapping human brain networks with cortico-cortical evoked potentials. Philos Trans R Soc Lond B Biol Sci (2014) 369(1653):20130528. doi:10.1098/rstb.2013.0528

101. Mandonnet E, Winkler PA, Duffau H. Direct electrical stimulation as an input gate into brain functional networks: principles, advantages and limitations. Acta Neurochir (2010) 152:185-93. doi:10.1007/s00701009-0469-0

102. Thiebaut de Schotten M, Urbanski M, Duffau H, Volle E, Lévy R, Dubois B, et al. Direct evidence for a parietal-frontal pathway subserving spatial awareness in humans. Science (2005) 309(5744):2226-8. doi:10.1126/ science.1116251 
103. Herbet G, Lafargue G, Moritz-Gasser S, Bonnetblanc F, Duffau H. Interfering with the neural activity of mirror-related frontal areas impairs mentalistic inferences. Brain Struct Funct (2015) 220(4):2159-69. doi:10.1007/ s00429-014-0777-x

104. Duffau H. Do brain tumours allow valid conclusions on the localisation of human brain functions. Cortex (2011) 47(8):1016-7. doi:10.1016/ j.cortex.2010.11.010

105. Hervey-Jumper SL, Berger MS. Technical nuances of awake brain tumor surgery and the role of maximum safe resection. J Neurosurg Sci (2015) 59(4):351-60.

106. Dziedzic T, Bernstein M. Awake craniotomy for brain tumor: indications, technique and benefits. Expert Rev Neurother (2014) 14(12):1405-15. doi:10.1586/14737175.2014.979793

107. Hervey-Jumper SL, Li J, Lau D, Molinaro AM, Perry DW, Meng L, et al. Awake craniotomy to maximize glioma resection: methods and technical nuances over a 27-year period. J Neurosurg (2015) 123(2):325-39. doi:10.3171/2014.1

108. Chacko AG, Thomas SG, Babu KS, Daniel RT, Chacko G, Prabhu K, et al. Awake craniotomy and electrophysiological mapping for eloquent area tumours. Clin Neurol Neurosurg (2013) 115(3):329-34. doi:10.1016/ j.clineuro.2012.10.022
109. Brown T, Shah AH, Bregy A, Shah NH, Thambuswamy M, Barbarite E, et al. Awake craniotomy for brain tumor resection: the rule rather than the exception? J Neurosurg Anesthesiol (2013) 25(3):240-7. doi:10.1097/ ANA.0b013e318290c230

110. Milian M, Tatagiba M, Feigl GC. Patient response to awake craniotomy a summary overview. Acta Neurochir (Wien) (2014) 156(6):1063-70. doi:10.1007/s00701-014-2038-4

111. Paldor I, Drummond KJ, Awad M, Sufaro YZ, Kaye AH. Is a wake-up call in order? Review of the evidence for awake craniotomy. J Clin Neurosci (2016) 23:1-7. doi:10.1016/j.jocn.2015.11.004

Conflict of Interest Statement: The authors declare that the research was conducted in the absence of any commercial or financial relationships that could be construed as a potential conflict of interest.

Copyright (c) 2017 Ghinda and Duffau. This is an open-access article distributed under the terms of the Creative Commons Attribution License (CC BY). The use, distribution or reproduction in other forums is permitted, provided the original author(s) or licensor are credited and that the original publication in this journal is cited, in accordance with accepted academic practice. No use, distribution or reproduction is permitted which does not comply with these terms. 